\title{
Severe obesity in a specialist type 2 diabetes outpatient clinic: an Australian retrospective cohort study
}

Arunav Thakur ${ }^{1}$, Dharmesh Sharma ${ }^{1}$, Bhavya Gupta ${ }^{1}$, Nikitha Kramadhari ${ }^{1}$, Rohit Rajagopal ${ }^{2}$, David Simmons ${ }^{1,2}$ and Milan Kumar Piya ${ }^{1,2^{*}}$

\begin{abstract}
Background: Obesity is a major risk factor for the development of type 2 diabetes (T2DM) and its complications. Significant weight loss has been shown to improve glycaemia in people with T2DM and obesity. National and international guidelines recommend considering bariatric surgery for body mass index (BMI) $\geq 35 \mathrm{~kg} / \mathrm{m}^{2}$. We assessed the proportion of people with T2DM meeting criteria for surgery, how many had been offered a bariatric/ obesity service referral, and compared the characteristics of people with $\mathrm{BMI} \geq 35 \mathrm{~kg} / \mathrm{m}^{2}$ and $\mathrm{BMI}<35 \mathrm{~kg} / \mathrm{m}^{2}$.

Methods: Retrospective data were collected for all people with T2DM aged $\geq 18$ years, attending a hospital specialist diabetes outpatient service over three calendar years, 2017-2019.

Results: Of 700 people seen in the service, 291 (42\%) had BMI $\geq 35 \mathrm{~kg} / \mathrm{m}^{2}$ (the "BMl $\geq 35$ group") and met criteria for bariatric surgery, but only 54 (19\%) of them were offered referral to an obesity service. The BMI $\geq 35$ group was younger than those with a BMl $<35 \mathrm{~kg} / \mathrm{m}^{2}(56.1 \pm 14.8$ vs $61.4 \pm 14.6$ years, $p<0.001)$ (mean \pm SD), with similar diabetes duration ( $11.0 \pm 9.0$ vs $12.3 \pm 8.9$ years, $p=0.078)$, and there was no significant difference in initial HbA1c ( $75 \pm 27$ vs $72 \pm 26 \mathrm{mmol} / \mathrm{mol}, p=0.118)(9.0 \pm 2.5$ vs $8.7 \pm 2.4 \%)$ or proportion treated with insulin (62\% vs $58 \%)$. There was more GLP1 agonist use in the BMI $\geq 35$ group (13\% vs 7\%, $p=0.003$ ) but similar rates of SGLT2 inhibitor use ( $25 \%$ vs $21 \%, p=0.202$ ). The $\mathrm{BMI} \geq 35$ group received more new medication and/or dose adjustments ( $74 \%$ vs $66 \%, p=0.016)$. Only $29 \%$ in the BMl $\geq 35 \mathrm{~kg}$ group achieved $\mathrm{HbA1c}<53 \mathrm{mmol} / \mathrm{mol}(7.0 \%)$.

Conclusions: In spite of frequently meeting the criteria for bariatric surgery and not achieving glycaemic targets, people with T2DM in this specialist clinic received limited medical or surgical management of their obesity. This study suggests opportunities for improvement in care of people with T2DM at several levels including increased referrals from T2DM services to weight management/bariatric services, as well as an increased use of GLP1 agonists and SGLT2 inhibitors where appropriate. Our data support the need to prioritise obesity management in the treatment of type 2 diabetes.
\end{abstract}

Keywords: Obesity, Health care delivery, Type 2 diabetes, Bariatric

\footnotetext{
* Correspondence: m.piya@westernsydney.edu.au

'School of Medicine, Western Sydney University, Campbelltown, New South

Wales 2560, Australia

${ }^{2}$ Macarthur Diabetes Service, Camden and Campbelltown Hospitals,

Campbelltown, New South Wales 2560, Australia
}

(c) The Author(s). 2021 Open Access This article is licensed under a Creative Commons Attribution 4.0 International License, which permits use, sharing, adaptation, distribution and reproduction in any medium or format, as long as you give appropriate credit to the original author(s) and the source, provide a link to the Creative Commons licence, and indicate if changes were made. The images or other third party material in this article are included in the article's Creative Commons licence, unless indicated otherwise in a credit line to the material. If material is not included in the article's Creative Commons licence and your intended use is not permitted by statutory regulation or exceeds the permitted use, you will need to obtain permission directly from the copyright holder. To view a copy of this licence, visit http://creativecommons.org/licenses/by/4.0/. The Creative Commons Public Domain Dedication waiver (http://creativecommons.org/publicdomain/zero/1.0/) applies to the data made available in this article, unless otherwise stated in a credit line to the data. 


\section{Background}

Type 2 diabetes mellitus (T2DM) is a growing problem with a worldwide prevalence of approximately $7 \%$ in adults, and a similar prevalence across Australia [1, 2]. Obesity is associated with an increase in mortality with increasing body mass index (BMI), and is a wellestablished risk factor for type 2 diabetes [3]. Obesity $\left(\mathrm{BMI} \geq 30 \mathrm{~kg} / \mathrm{m}^{2}\right)$ prevalence worldwide is $13 \%$ [4], and $11 \%$ of adults in Australia are living with severe obesity $\left(\mathrm{BMI} \geq 35 \mathrm{~kg} / \mathrm{m}^{2}\right)$ [5]. Beyond the major health challenge, the additional annual total health cost, in comparison to those with a normal weight without diabetes, is $26 \%$ for obesity alone and $46 \%$ for people with obesity and diabetes [6].

Glycaemic control is important in the context of T2DM, particularly in reducing the risk of microvascular complications [7]. In addition, the 10-year follow-up data from United Kingdom Prospective Diabetes Study showed a continued reduction in microvascular and macrovascular risk for participants who underwent intensive glucose control, suggesting a benefit from early good control, the legacy effect [8]. However, in people with longstanding T2DM, particularly those with existing cardiovascular disease or risk factors, the benefits of pushing glycaemic targets lower to reduce cardiovascular disease and mortality are less clear [9]. Weight loss, if significant and sustained, can improve glycaemic control as shown in the DiRECT trial, DIADEM-1 trial and Look AHEAD study [10-12]. However, sustained weight loss is difficult to achieve in clinical practice, whether it be with lifestyle or pharmacotherapy. In spite of this, weight and diabetes outcomes have been shown to be significantly better for people with obesity and T2DM in a multidisciplinary obesity service when compared to a hospital diabetes clinic [13]. Bariatric surgery is also an established treatment option for severe obesity and T2DM, and can result in significant, sustained weight loss and improvement/remission of T2DM [14, 15]. Bariatric surgery data and the DiRECT and DIADEM-1 trials have all shown that intervening soon after the diagnosis of T2DM is necessary for diabetes remission with weight loss $[10,11,16]$. Hence, the European Association for the Study of Diabetes (EASD) - American Diabetes Association (ADA) consensus guidelines for T2DM management recommend treating obesity, alongside glycaemia, with weight-lowering medications and bariatric surgery [17].

The bulk of T2DM is managed in primary care with only a small proportion being seen in a specialist diabetes clinic, usually those with diabetes complications. These clinics are limited in numbers and average local waiting times to see new patients are over 6 months from referral date, with similar waiting times in nearby publicly funded clinics and shorter waiting times of 2-3 months in private clinics. Various models of integrated care have been proposed to improve patient care and reduce the burden on specialist clinics $[18,19]$.

In Australia, the National Health and Medical Research Council (NHMRC) Guidelines recommend considering bariatric surgery for people with T2DM and a $\mathrm{BMI} \geq 35 \mathrm{~kg} / \mathrm{m}^{2}$ [20]. This is corroborated by multiple international guidelines including the UK National Institute for Health and Clinical Excellence (NICE) guidelines and Diabetes Surgery Summit [21, 22]. Between July 2018 and June 2019, less than 10\% of primary bariatric surgeries in Australia were publicly funded [23], and there is limited access to publicly funded specialised obesity services as reported in a position statement by the Clinical Obesity Services in Public Hospitals (COSIPH) in Australia [24]. As a result, many people with severe obesity and T2DM may not receive timely referrals to obesity services or have bariatric surgery discussed, as it is not readily available for them. At the same time, specialist diabetes clinics in hospitals may not be able to provide timely optimal management for T2DM or help with weight management. Therefore, in people with T2DM attending a specialist diabetes outpatient clinic, our aims were:

1. To describe the proportion that met the recommended criteria for bariatric surgery using a cut-off of $\geq 35 \mathrm{~kg} / \mathrm{m}^{2}$.

2. To compare the characteristics and outcomes in people with a BMI $\geq 35 \mathrm{~kg} / \mathrm{m}^{2}$ to those with a $\mathrm{BMI}<35 \mathrm{~kg} / \mathrm{m}^{2}$.

3. To determine the proportion of people with $\mathrm{BMI} \geq$ $35 \mathrm{~kg} / \mathrm{m}^{2}$ that were referred to the metabolic clinic or had bariatric surgery discussed with them as an option.

4. To compare metabolic outcomes between people who were new to the clinic, and people who had been attending the clinic in previous years.

\section{Participants and methods \\ Design}

Retrospective data were collected for all non-pregnant adults with T2DM attending the specialist diabetes outpatient service in a public teaching hospital in Sydney.

The following inclusion criteria were applied:

- Type 2 diabetes

- Age $\geq 18$

- Had attended an appointment with an endocrinologist for type 2 diabetes between 01/01/ 17 and 31/12/19

A list of all people who saw an endocrinologist across the three calendar years was generated from the 
hospital's electronic medical records. The database was then filtered to exclude type 1 diabetes, diabetes in pregnancy, or people with a general endocrine/thyroid condition alone. This database was then cross-checked with patient notes and correspondence letters to select all the people with T2DM. Those with no recorded height were excluded due to the inability to calculate their BMI. The data collection flow chart is shown in Fig. 1.

Patient electronic medical records (eMR) were used to obtain demographic data, pathology results, anthropometric data, use of insulin and other anti-diabetes medications, complications of diabetes, annual screening, patient education and referrals or discussions of bariatric surgery. This was corroborated by checking patient correspondence letters. The study was approved by the South West Sydney Local Health District (SWSLHD) Research Ethics Committee as a quality improvement project (Reference: CT20_2018).

We compared baseline data and follow up metabolic outcomes in people with a $\mathrm{BMI} \geq 35 \mathrm{~kg} / \mathrm{m}^{2}$ to those with a $\mathrm{BMI}<35 \mathrm{~kg} / \mathrm{m}^{2}$. Some people only had one $\mathrm{HbA1c}$ reading available in a calendar year, and hence they had to be excluded when calculating HbA1c reduction and proportion reaching $\mathrm{HbA} 1 \mathrm{c}<53 \mathrm{mmol} / \mathrm{mol}$ (7.0\%). Amongst the $\mathrm{BMI} \geq 35 \mathrm{~kg} / \mathrm{m}^{2}$ group, we also compared outcomes in people who were new referrals to the clinic to existing patients who had been attending the clinic in previous years.

A formal sample size calculation was not performed, but the number of patients across 3 years was felt to be adequate for the specified outcomes. Data were analysed using SPSS software, version 26 (SPSS Inc., Chicago, Ill, USA). Distribution of continuous variables was tested for normality using the Kolmogorov-Smirnov test. Means and standard deviations were computed for continuous variables and frequencies and percentages for categorical variables. T-tests were performed for continuous variables and chi-square tests for categorical variables. $P$-value of $<0.05$ was considered statistically significant. All tests were 2 tailed.

\section{Results}

Of the 700 eligible people, $42 \%$ had a BMI $\geq 35 \mathrm{~kg} / \mathrm{m}^{2}$. Almost a quarter of people (23\%) had a BMI $\geq 40 \mathrm{~kg} / \mathrm{m}^{2}$. The BMI $\geq 35 \mathrm{~kg} / \mathrm{m}^{2}$ group was younger, with a similar diabetes duration, and a higher proportion of women (Table 1 ). Among the BMI $\geq 35 \mathrm{~kg} / \mathrm{m}^{2}$ people, only $19 \%$ $(n=54)$ were either offered referral to an obesity clinic, or had bariatric surgery discussed with them. The BMI $\geq$ $35 \mathrm{~kg} / \mathrm{m}^{2}$ group attended a higher number of dietitian appointments on average $(0.3 \pm 0.7$ vs $0.2 \pm 0.5, p=$ $0.019)$ but there was no difference between both groups for endocrinologist $(1.8 \pm 1.6$ vs $1.9 \pm 1.8)$ and diabetes educator (specialist nurse) appointments $(0.7 \pm 1.3$ vs $0.7 \pm 1.3$ ) (Table 2). There was no statistical difference in starting HbA1c $(75 \pm 27$ vs $72 \pm 26 \mathrm{mmol} / \mathrm{mol}, p=0.118$ ) $(9.0 \pm 2.5$ vs $8.7 \pm 2.4 \%)$ and the two groups had a similar reduction in $\mathrm{HbA} 1 \mathrm{c}$ between their first and last readings $(15 \pm 28$ vs $14 \pm 28 \mathrm{mmol} / \mathrm{mol}) \quad(-1.4 \pm 2.6$ vs $-1.2 \pm$ 2.5\%) (Table 2).

A similar proportion of people were treated with insulin $(62 \%$ vs $58 \%)$ and oral anti-diabetes agents including

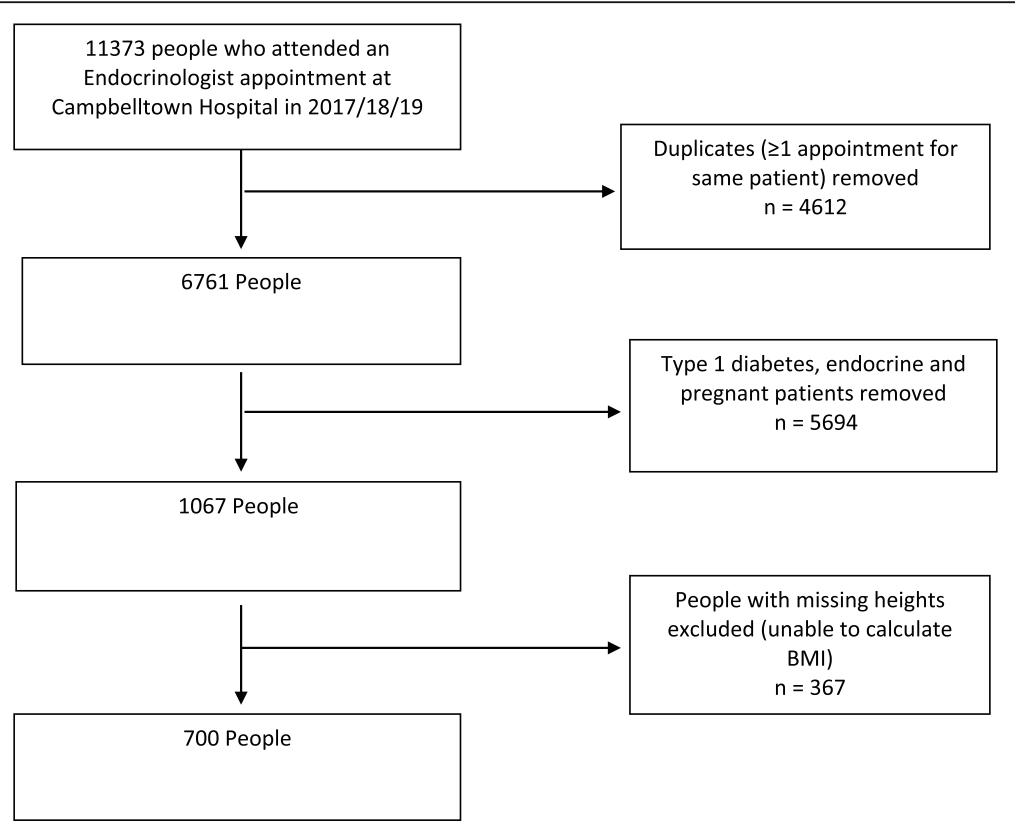

Fig. 1 Data Collection Flowchart 
Table 1 Baseline Data

\begin{tabular}{|c|c|c|c|}
\hline Measure & $\mathrm{BMI} \geq 35 \mathrm{~kg} / \mathrm{m}^{2}(n=291) 42 \%$ & BMI $<35 \mathrm{~kg} / \mathrm{m}^{2}(n=409) 58 \%$ & $P$ value \\
\hline Age & $56.1 \pm 14.8$ & $61.4 \pm 14.6$ & $<0.001$ \\
\hline \%Women & $53.3 \%(n=155)$ & $42.3 \%(n=173)$ & 0.004 \\
\hline Weight (kg) & $119.6 \pm 24.3$ & $81.9 \pm 16.2$ & $<0.001$ \\
\hline BMI $\left(\mathrm{kg} / \mathrm{m}^{2}\right)$ & $42.5 \pm 7.0$ & $28.8 \pm 3.8$ & $<0.001$ \\
\hline Duration of Diabetes (years) & $11.0 \pm 9.0$ & $12.3 \pm 8.9$ & 0.078 \\
\hline \%Smoker/Ex-Smoker & $31 \%(n=90)$ & $28 \%(n=115)$ & 0.421 \\
\hline Hypertension & $70 \%(n=202)$ & $66 \%(n=268)$ & 0.270 \\
\hline Systolic BP & $131 \pm 18$ & $130 \pm 18$ & 0.265 \\
\hline Diastolic BP & $76 \pm 11$ & $75 \pm 11$ & 0.418 \\
\hline Dyslipidaemia & $59 \%(n=171)$ & $59 \%(n=241)$ & 0.939 \\
\hline Cholesterol Medication & $53 \%(n=154)$ & $61 \%(n=247)$ & 0.047 \\
\hline Total cholesterol & $4.5 \pm 1.3$ & $4.2 \pm 1.4$ & 0.138 \\
\hline LDL & $2.3 \pm 1.0$ & $2.2 \pm 0.9$ & 0.223 \\
\hline $\mathrm{HDL}$ & $1.1 \pm 0.3$ & $1.2 \pm 0.9$ & 0.504 \\
\hline Triglycerides & $2.8 \pm 1.8$ & $2.7 \pm 3.4$ & 0.786 \\
\hline Obstructive Sleep Apnoea & $25 \%(n=73)$ & $6 \%(n=24)$ & $<0.001$ \\
\hline Ischaemic Heart Disease & $25 \%(n=71)$ & $26 \%(n=104)$ & 0.734 \\
\hline Stroke & $9.7 \%(n=28)$ & $7.9 \%(n=32)$ & 0.411 \\
\hline Chronic Kidney Disease Stage 3 or below & $19 \%(n=55)$ & $22 \%(n=91)$ & 0.261 \\
\hline eGFR & $70.2 \pm 22.8$ & $67.7 \pm 23.9$ & 0.217 \\
\hline Abnormal Urine ACR & $51 \%(n=107)$ & $47 \%(n=116)$ & 0.838 \\
\hline Peripheral Vascular Disease & $6.2 \%(n=18)$ & $5.4 \%(n=22)$ & 0.660 \\
\hline Peripheral Neuropathy & $18 \%(n=52)$ & $18 \%(n=73)$ & 0.987 \\
\hline Current/Previous Foot ulcer & $8.6 \%(n=25)$ & $3.9 \%(n=16)$ & 0.009 \\
\hline Previous lower limb amputations & $4.1 \%(n=12)$ & $2.4 \%(n=10)$ & 0.210 \\
\hline Laser treatment for Diabetic Retinopathy & $4.3 \%(n=12)$ & $6.4 \%(n=26)$ & 0.257 \\
\hline Depression & $16 \%(n=46)$ & $11 \%(n=44)$ & 0.049 \\
\hline Starting $\mathrm{HbA} 1 \mathrm{c}$ & $75 \pm 27 \mathrm{mmol} / \mathrm{mol}(9.0 \pm 2.5 \%)$ & $72 \pm 26 \mathrm{mmol} / \mathrm{mol}(8.7 \pm 2.4 \%)$ & 0.118 \\
\hline$\%$ on Insulin & $62 \%(n=180)$ & $58 \%(n=235)$ & 0.252 \\
\hline Total daily dose of insulin (units) & $59.9 \pm 49.3$ & $37.2 \pm 26.0$ & 0.004 \\
\hline
\end{tabular}

eGFR Estimated glomerular filtration rate, $A C R$ Albumin/creatinine ratio, $L D L$ Low density lipoprotein, $H D L$ High density lipoprotein, $B P$ Blood pressure

SGLT2 inhibitors, with fewer patients in the BMI $\geq 35$ $\mathrm{kg} / \mathrm{m}^{2}$ group on sulphonylureas (31\% vs $39 \%$ ) (Fig. 2). In the $\mathrm{BMI} \geq 35 \mathrm{~kg} / \mathrm{m}^{2}$ group, there was more GLP1 receptor agonist use $(13 \%$ vs $6.6 \%, p=0.003)$ but less DPP4i use ( $23 \%$ vs $32 \%, p=0.015$ ) (Fig. 2). The BMI $\geq 35 \mathrm{~kg} / \mathrm{m}^{2}$ group had a higher total daily insulin dose $(59.9 \pm 49.3$ vs $37.2 \pm 26.0, p=0.004$ ) (Table 1 ) and a higher rate of lipohypertrophy $(5.3 \%$ vs $2.0 \%, p=0.019)$, but suffered from less documented hypoglycaemia (21\% vs $30 \%, p=$ 0.007) (Table 2). There was also less cholesterollowering medication use in the $\mathrm{BMI} \geq 35 \mathrm{~kg} / \mathrm{m}^{2}$ group (53\% vs $61 \%, p=0.047$ ) (Table 1 ). Obstructive sleep apnoea $(25 \%$ vs $5.9 \%, p<0.001)$, foot ulcers $(8.6 \%$ vs $3.9 \%$, $p=0.009)$ and depression (16\% vs $11 \%, p=0.049)$ were more prevalent in the $\mathrm{BMI} \geq 35 \mathrm{~kg} / \mathrm{m}^{2}$ group, with no difference in other co-morbidities including hypertension, dyslipidaemia, ischaemic heart disease, stroke, chronic kidney disease, peripheral vascular disease, peripheral neuropathy, autonomic neuropathy and diabetic retinopathy (Table 1). People with a BMI $\geq 35 \mathrm{~kg} / \mathrm{m}^{2}$ were more likely to have additional medications/dose increases to diabetes medications during their consultation ( $74 \%$ vs $66 \%, p=0.016$ ), but there were no differences in annual screening, or patient education regarding hypoglycaemia, driving, and target HbA1c.

Table 3 compares new patients to the clinic and existing clinic patients with $\mathrm{BMI} \geq 35 \mathrm{~kg} / \mathrm{m}^{2}$. New patients had a higher HbA1c, shorter diabetes duration, greater metformin therapy, educator and dietitian attendance, and had a greater $\mathrm{HbA1c}$ reduction in clinic than 
Table 2 Glycaemic control and clinic attendance

\begin{tabular}{|c|c|c|c|}
\hline Measure & $\begin{array}{l}\mathrm{BMI} \geq 35 \mathrm{~kg} / \mathrm{m}^{2}(n=291) \\
42 \%\end{array}$ & $\begin{array}{l}\mathrm{BMI}<35 \mathrm{~kg} / \mathrm{m}^{2}(n=409) \\
58 \%\end{array}$ & $\begin{array}{l}P \\
\text { value }\end{array}$ \\
\hline Final $\mathrm{HbA1c^{a }}$ & $66 \pm 20 \mathrm{mmol} / \mathrm{mol}(8.2 \pm 1.8 \%)$ & $62 \pm 19 \mathrm{mmol} / \mathrm{mol}(7.8 \pm 1.7 \%)$ & 0.073 \\
\hline $\mathrm{HbA} 1 \mathrm{c}$ reduction $\%{ }^{\mathrm{a}}$ & $15 \pm 28 \mathrm{mmol} / \mathrm{mol}(1.4 \pm 2.6 \%)$ & $14 \pm 28 \mathrm{mmol} / \mathrm{mol}(1.2 \pm 2.5 \%)$ & 0.661 \\
\hline$\%$ achieving $\mathrm{HbA} 1 \mathrm{c}<53 \mathrm{mmol} / \mathrm{mol}(7.0 \%)^{a}$ & $29 \%$ & $39 \%$ & 0.092 \\
\hline$\%$ with $\mathrm{HbA} 1 \mathrm{c}>75 \mathrm{mmol} / \mathrm{mol}(9.0 \%)^{a}$ & $29 \%$ & $19 \%$ & 0.066 \\
\hline Documented hypoglycaemia & $21 \%(n=59)$ & $30 \%(n=121)$ & 0.007 \\
\hline Frequent hypoglycaemic episodes & $9.5 \%(n=27)$ & $14 \%(n=56)$ & 0.084 \\
\hline Documented severe hypoglycaemia & $1.4 \%(n=4)$ & $2.3 \%(n=9)$ & 0.418 \\
\hline Lipohypertrophy & $5.3 \%(n=15)$ & $2.0 \%(n=8)$ & 0.019 \\
\hline Endocrinologist Appointments Attended/patient & $1.8 \pm 1.6$ & $1.9 \pm 1.8$ & 0.788 \\
\hline $\begin{array}{l}\text { Total Diabetes Specialist Nurse (Educator) Appointments Attended/ } \\
\text { patient }\end{array}$ & $0.7 \pm 1.3$ & $0.7 \pm 1.3$ & 0.998 \\
\hline Total Dietician Appointments Attended/patient & $0.3 \pm 0.7$ & $0.2 \pm 0.5$ & 0.019 \\
\hline
\end{tabular}

${ }^{a} n=153(\mathrm{BMI} \geq 35)$ and $n=119(\mathrm{BMI}<35)$ had $2 \mathrm{HbA1c}$ readings available

existing clinic patients. Existing patients were more likely to be treated with insulin and/or sulphonylureas, but there was no significant difference in new diabetes agent use (SGLT2 inhibitors and GLP-1 receptor agonists). In the $B M I \geq 35 \mathrm{~kg} / \mathrm{m}^{2}$ group, HbA1c dropped significantly for people in their first year of attendance, but not for those who had attended the clinic in previous years $(-18 \pm 31$ vs $3 \pm 16 \mathrm{mmol} / \mathrm{mol}, p<0.001)(-1.6 \pm 2.8$ vs $-0.3 \pm$ $1.4 \%$ ) (Table 3). However, there was no difference in the proportion reaching $\mathrm{HbAlc}<53 \mathrm{mmol} / \mathrm{mol}$ (7\%) in the first year of clinic attended between those with $\mathrm{BMI} \geq 35 \mathrm{~kg} / \mathrm{m}^{2}$ and $\mathrm{BMI}<35 \mathrm{~kg} / \mathrm{m}^{2}$ groups $(31 \%$ vs $38 \%, p=0.261)$.

\section{Discussion}

This study showed that almost half of the people attending the specialist T2DM clinic have a BMI $\geq 35 \mathrm{~kg} / \mathrm{m}^{2}$ and meet the criteria for bariatric surgery, and less than a quarter achieve an $\mathrm{HbA} 1 \mathrm{c}<53 \mathrm{mmol} / \mathrm{mol}(7 \%)$. However, only 1 in 5 of the people that met the criteria were offered a referral to an obesity/metabolic clinic or for bariatric surgery. This study also showed that the BMI $\geq 35 \mathrm{~kg} / \mathrm{m}^{2}$ group were younger but already had diabetes for an average of 11 years, had higher insulin requirements and were more likely to have additional medications or doses added to their regimen during consultation. They had a similar diabetes duration to the $\mathrm{BMI}<35 \mathrm{~kg} / \mathrm{m}^{2}$ group, with no difference in initial HbA1c.

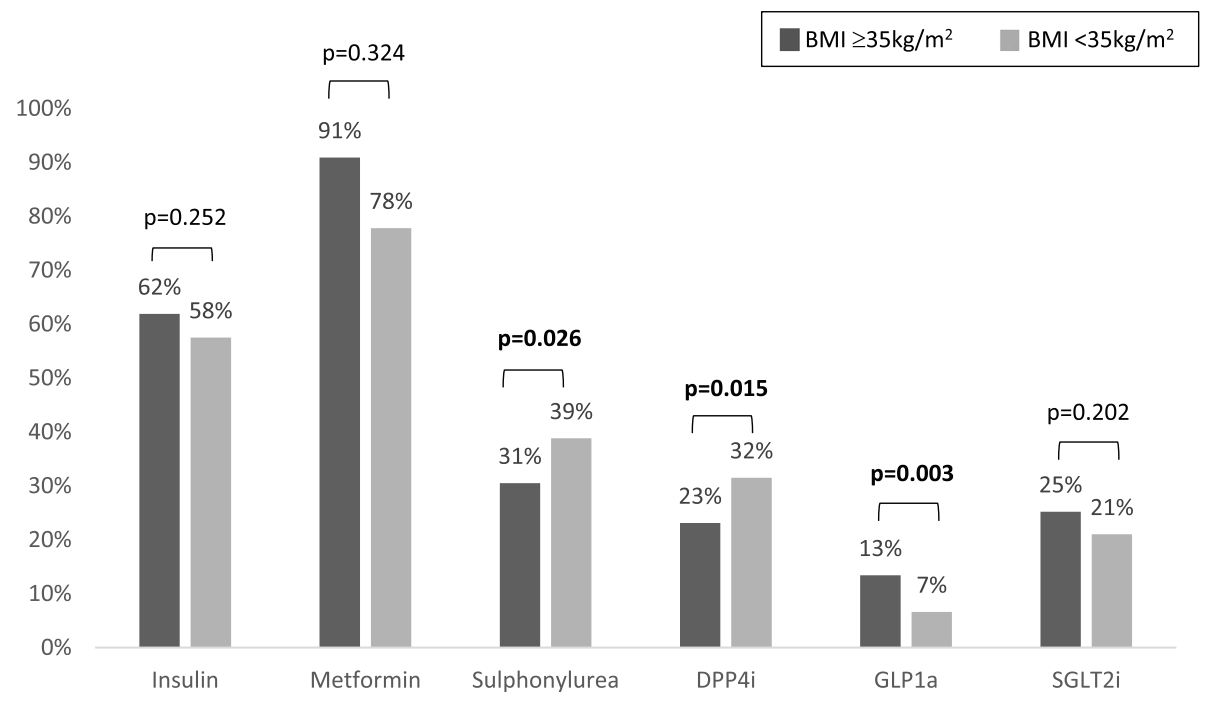

Fig. 2 Use of different classes of medications. DPP4i - Dipeptidyl-Peptidase 4, GLP1a - Glucagon-like Peptide 1 agonist, SGLT2i - Sodium/glucose Co-transporter 2 inhibitor 
Table 3 New People (first year in clinic) vs Existing People (from previous years) (BMI $\geq 35 \mathrm{~kg} / \mathrm{m}^{2}$ )

\begin{tabular}{|c|c|c|c|}
\hline Measure & New $(n=208) 50 \%$ & Existing $(n=207) 50 \%$ & $P$ value \\
\hline Age & $54.2 \pm 14.9$ & $61.0 \pm 12.4$ & $<0.001$ \\
\hline \%Women & $51 \%(n=107)$ & $56 \%(n=116)$ & 0.348 \\
\hline Weight (kg) & $120.6 \pm 24.8$ & $118.4 \pm 21.4$ & 0.334 \\
\hline $\mathrm{BMI}\left(\mathrm{kg} / \mathrm{m}^{2}\right)$ & $42.4 \pm 7.2$ & $42.8 \pm 6.5$ & 0.570 \\
\hline Duration of Diabetes (years) & $10.0 \pm 9.0$ & $13.5 \pm 8.6$ & $<0.001$ \\
\hline Starting $\mathrm{HbAlc}^{\mathrm{a}}$ & $78 \pm 27 \mathrm{mmol} / \mathrm{mol}(9.3 \pm 2.5 \%)$ & $66 \pm 21 \mathrm{mmol} / \mathrm{mol}(8.2 \pm 1.9 \%)$ & $<0.001$ \\
\hline $\mathrm{HbA} 1 \mathrm{c}$ reduction (\%) ${ }^{\mathrm{a}}$ & $18 \pm 31 \mathrm{mmol} / \mathrm{mol}(1.6 \pm 2.8 \%)$ & $3 \pm 16 \mathrm{mmol} / \mathrm{mol}(0.3 \pm 1.4 \%)$ & $<0.001$ \\
\hline$\%$ achieving $\mathrm{HbA} 1 \mathrm{c}<53 \mathrm{mmol} / \mathrm{mol}(7.0 \%)^{\text {a }}$ & $31 \%$ & $23 \%$ & 0.205 \\
\hline$\%$ with $\mathrm{HbA} 1 \mathrm{c}>75 \mathrm{mmol} / \mathrm{mol}(9.0 \%)^{a}$ & $33 \%$ & $22 \%$ & 0.116 \\
\hline$\%$ on Insulin & $59 \%(n=123)$ & $70 \%(n=144)$ & 0.027 \\
\hline Metformin & $83 \%(n=173)$ & $75 \%(n=156)$ & 0.041 \\
\hline Sulphonylurea & $27 \%(n=56)$ & $41 \%(n=85)$ & 0.003 \\
\hline DPP4i & $25 \%(n=51)$ & $24 \%(n=49)$ & 0.842 \\
\hline GLP1 agonist & $18 \%(n=37)$ & $20 \%(n=41)$ & 0.684 \\
\hline SGLT2i & $23 \%(n=48)$ & $32 \%(n=65)$ & 0.057 \\
\hline Endocrinologist Appointments Attended/patient & $1.8 \pm 1.8$ & $1.8 \pm 0.9$ & 0.878 \\
\hline Total Diabetes Specialist Nurse (Educator) Appointments Attended/patient & $0.8 \pm 1.5$ & $0.4 \pm 0.9$ & $<0.001$ \\
\hline Total Dietician Appointments Attended/patient & $0.4 \pm 0.7$ & $0.2 \pm 0.5$ & $<0.001$ \\
\hline
\end{tabular}

DPP4i Dipeptidyl peptidase-4 inhibitor, GLP1 agonist Glucagon-like peptide-1 receptor agonist, SGLT2i Sodium-glucose transport protein 2 inhibitor

${ }^{a} n=94$ (new) and $n=82$ (existing) had $2 \mathrm{HbA1c}$ readings available

The high proportion of people with BMI $\geq 35 \mathrm{~kg} / \mathrm{m}^{2}$ in our clinic aligns with an audit of a specialist diabetes clinic in the UK, which revealed that $52 \%$ of participants with T2DM had obesity (BMI $\geq 30 \mathrm{~kg} / \mathrm{m}^{2}$ ) and a further $8.1 \%$ had a $B M I \geq 40 \mathrm{~kg} / \mathrm{m}^{2}$ [25]. The people with obesity were younger, had worse glycaemic control, higher blood pressures, and were more likely to be on an antihypertensive or lipid lowering medication compared to the people with a BMI $<30 \mathrm{~kg} / \mathrm{m}^{2}$ [25]. Data from the UK's National Diabetes Audit (NDA) showed little association between BMI and adverse outcomes, apart from an inverse gradient for stroke and MI. Similarly, in our study, the $\mathrm{BMI} \geq 35 \mathrm{~kg} / \mathrm{m}^{2}$ did not have a higher rate of microvascular or macrovascular complications compared to the $\mathrm{BMI}<35 \mathrm{~kg} / \mathrm{m}^{2}$ group [26], although the BMI $\geq 35$ $\mathrm{kg} / \mathrm{m}^{2}$ group was younger. As expected, the prevalence of OSA was much higher in the $\mathrm{BMI} \geq 35 \mathrm{~kg} / \mathrm{m}^{2}$ group $(26 \%$ vs $6.5 \%, p<0.001)$ [27]. It is possible that many people in this diabetes clinic have undiagnosed OSA, given that previous studies have demonstrated much higher prevalence of OSA in a specialist diabetes outpatient population [27]. The $\mathrm{BMI} \geq 35 \mathrm{~kg} / \mathrm{m}^{2}$ group also had a higher prevalence of foot ulcers, thus aligning with a previous study which showed a positive correlation between obesity and diabetic foot ulcers [28].

The low proportion of referrals for surgery or obesity/ metabolic clinics in our study may be attributed to a combination of lack of publicly funded obesity services and availability of bariatric surgery [23, 24]. However, previous studies have shown that there is also a reluctance in both patients and health care professionals to opt for bariatric surgery due to bias, negative media and attitudes towards weight-loss surgery [29, 30]. Data from our local weight management program has shown that in people with $\mathrm{T} 2 \mathrm{DM}$ and a $\mathrm{BMI} \geq 40 \mathrm{~kg} / \mathrm{m}^{2}$ benefitted from improved glycaemic control and reduced diabetic medication load after 6 months of attending the clinic [31], significantly more so than the $B M I \geq 35 \mathrm{~kg} / \mathrm{m}^{2}$ population in this study. Another retrospective cohort study from Australia, consisting of people with T2DM and $\mathrm{BMI} \geq 30 \mathrm{~kg} / \mathrm{m}^{2}$, compared glycaemic control in participants attending a multidisciplinary weight management clinic to participants receiving "best practice" care in a specialist diabetes clinic [13]. At 30 months, the people attending the weight management clinic achieved a greater $\mathrm{HbA1c}$ reduction than those attending the diabetes clinic [13]. This suggests that our BMI $\geq 35 \mathrm{~kg} / \mathrm{m}^{2}$ population, who had similar baseline characteristics to the participants in the cohort study, are more likely to achieve better glycaemic control by attending a weight management clinic even if bariatric surgery was not available to the patient. This may be because of the multidisciplinary nature of weight management programs that have greater dietitian and psychologist support in weight management programs, with the data here showing very few patients in the clinic were seen by 
a dietitian or diabetes specialist nurse, while a psychologist was not part of the T2DM service. Therefore, the $\mathrm{BMI} \geq 35 \mathrm{~kg} / \mathrm{m}^{2}$ group may have been better served in the multidisciplinary obesity service, leaving more capacity for the specialist diabetes clinic to see more patients with T2DM and its complications.

In the Look AHEAD trial, people with type 2 diabetes and overweight/obesity who received intensive lifestyle intervention for weight loss had a lower HbA1c, reduced sleep apnoea, reduced diabetes medication requirements, improved mobility and quality of life, fewer hospitalisations, and reduced healthcare costs [9]. With regards to bariatric surgery, a study of 5-year outcomes comparing bariatric surgery to medical therapy revealed that participants with type 2 diabetes who underwent surgery alongside medical therapy were far more likely to achieve the $\mathrm{HbA} 1 \mathrm{c}<6 \%$ target than those receiving medical therapy alone [32]. In addition, a post-hoc analysis of participants from the Swedish Obese Subjects Study revealed that bariatric surgery was associated with a reduced risk of microvascular complications in patients with diabetes [33]. Bariatric surgery data have also shown that diabetes duration is important in predicting who is likely to achieve diabetes remission [16]. The DiRECT and DIADEM-1 trials also highlighted the importance of intervening soon after the diagnosis of T2DM for diabetes remission with weight loss $[10,11]$. Thus, these studies suggest that the presence of obesity should be recognised early on in type 2 diabetes and managed alongside glycaemia, with timely referrals to obesity clinics or for bariatric surgery if appropriate, as significant sustained weight loss can improve glycaemic control, overall health, and lead to remission of diabetes. Recognising this, the local service is now piloting a Diabetes Remission Service in collaboration with primary care, based on the DiRECT study model.

The American Diabetes Association (ADA) guidelines recommend the use of weight lowering anti-diabetes medications in people with T2DM and obesity [34]. In our BMI $\geq 35 \mathrm{~kg} / \mathrm{m}^{2}$ group, use of weight-lowering medications was limited with less than 1 in 5 participants on a GLP1 agonist and only a quarter on an SGLT2 inhibitor. Data from the Australian National Diabetes Audit (ANDA) showed that in 2019, 27\% of people with T2DM were on an SGLT2 inhibitor and $12 \%$ were on a GLP1 receptor agonist [35]. Although our use of weight lowering medications in the $\mathrm{BMI} \geq 35 \mathrm{~kg} / \mathrm{m}^{2}$ group was comparable to that of the ANDA, the figures in our specialist clinic should have been higher as the mean BMI of the ANDA population was only $33.5 \mathrm{~kg} / \mathrm{m}^{2}$ [35]. However, some of these agents like GLP1 agonists and SGLT2 inhibitors are relatively new and are more expensive than the traditional therapies including sulphonylureas and insulin, which treating clinicians may be more familiar with. Unlike the weight-lowering agents, sulphonylureas are associated with weight gain [34]. In our BMI $\geq 35 \mathrm{~kg} / \mathrm{m}^{2}$ group, sulphonylurea use was appropriately lower than in the BMI $<35 \mathrm{~kg} / \mathrm{m}^{2}$ group.

This study also showed that new patients to the clinic saw an improvement in $\mathrm{HbA1c}$ in the first year, but there was no ongoing further improvement in glycaemia, although the initial benefit seemed to be maintained. We have recently evaluated a locality-based integrated diabetes care service in a neighbouring local government area which showed similar results where even a few years after patients were discharged following specialist diabetes team review, their $\mathrm{HbA1c}$ reductions were maintained [19], raising the potential for early discharge of patients from the T2DM clinic after several visits, to create more capacity in the T2DM clinic without compromising patient care. As a result, this would increase capacity in the already strained public T2DM clinic.

This study has some limitations. This is a single centre study of a publicly funded specialist diabetes clinic. However, there are several endocrinologists practising within this clinic. A proportion of people were excluded from the study as their records did not contain a height or weight. There was also a lack of serial weight measurements for the majority of patients which may indicate that staff in the specialist clinic were more focussed on glycaemic control rather than obesity management. Furthermore, some people only attended the clinic once, which made it difficult to assess their progress in regards to weight loss and glycaemic control. The retrospective study design does not account for discussions regarding bariatric surgery or referral to a metabolic clinic which were not documented. A major strength of this study is that all eligible people who attended the clinic were included in the study.

\section{Conclusions}

The results from this study provide a basis for future policy and clinical practice. Many people who attended the public T2DM clinic met the NHMRC criteria for bariatric surgery, but were often not offered a referral to an obesity service or had bariatric surgery discussed as a therapeutic option. This study suggests opportunities for improvement in care of people with T2DM at several levels. Increased referrals from T2DM services to weight management/bariatric services is recommended, along with an increased use of GLP1 agonists and SGLT2 inhibitors where appropriate. The potential for discharge of people who have been treated for over a year in a specialist service has also been highlighted, as has the importance of early recognition of T2DM and management of weight in primary care to provide a chance for diabetes remission, given the long duration of diabetes among the patients seen in a specialist T2DM service. Therefore, the results of this study support the need to systematically consider obesity management in the overall structured management of T2DM. 


\section{Abbreviations}

T2DM: Type 2 Diabetes Mellitus; BMI: Body Mass Index; GLP1: Glucagon-like Peptide 1; SGLT2: Sodium/glucose Co-transporter 2; UKPDS: United Kingdom Prospective Diabetes Study; EASD-ADA: European Association of the Study of Diabetes and American Diabetes Association; NHMRC: National Health and Medical Research Medical Council; BP: Blood Pressure; LDL: Low density Lipoprotein; HDL: High Density Lipoprotein; eGFR: Estimated Glomerular Filtration Rate; ACR: Albumin/Creatinine Ratio; DPP4i: Dipeptidyl-peptidase 4; NDA: National Diabetes Audit; ANDA: Australian National Diabetes Audit

\section{Acknowledgements}

The authors thank Vanessa Monty for assistance with collating outpatient clinic data, and Kyaw Phone Myint for help with the database.

\section{Authors' contributions}

AT carried out data collection, data analysis, and writing of the original draft. DSh performed data collection and statistical analysis. BG and NK were involved in data curation and review of the original draft. RR and DS participated in the design of the study and were involved in editing the manuscript. MKP conceived of the study, participated in its design and supervision, and helped to draft the manuscript. All authors read and approved the final manuscript.

\section{Funding}

AT, DSh, BG, and NK received funding from Western Sydney University through the Summer Research Scholarship program to do this work.

\section{Availability of data and materials}

The datasets used and/or analysed during the current study are hospital patient data that would not be freely available. For further details of the type of data used and any specific questions, please contact the corresponding author.

\section{Declarations}

\section{Ethics approval and consent to participate}

The study was approved as a Quality Improvement Project by the South West Sydney Local Health District (SWSLHD) Human Research Ethics Committee (HREC) (Reference: CT20_2018). As part of this approval, a waiver of individual patient consent was approved by the SWSLHD HREC, and this study was conducted in accordance with the Declaration of Helsinki.

\section{Consent for publication}

Not applicable.

\section{Competing interests}

The authors have no conflict of interest to declare.

Received: 14 December 2020 Accepted: 11 March 2021

Published online: 24 March 2021

\section{References}

1. International Diabetes Federation. IDF Diabetes Atlas. 9th ed; 2019. [cited 6 August 2020]. Available from: https://www.diabetesatlas.org/upload/ resources/2019/IDF_Atlas_9th_Edition_2019.pdf

2. Diabetes, Type 2 diabetes - Australian Institute of Health and Welfare. Australian institute of health and welfare. 2020 [cited 6 August 2020]. Available from: https://www.aihw.gov.au/reports/diabetes/diabetes-sna pshot/contents/how-many-australians-have-diabetes/type-2-diabetes

3. Di Angelantonio E, Bhupathiraju S, Wormser D, Gao P, Kaptoge S, de Gonzalez A, et al. Body-mass index and all-cause mortality: individualparticipant-data meta-analysis of 239 prospective studies in four continents. Lancet. 2016;388(10046):776-86. https://doi.org/10.1016/S0140-6736(16)301 75-1.

4. World Health Organisation. Obesity and overweight: WHO; 2020. [cited 6 August 2020]. Available from: https://www.who.int/news-room/fact-sheets/ detail/obesity-and-overweight

5. A picture of overweight and obesity in Australia. Australian institute of health and welfare. 2019 [cited 6 August 2020]. Available from: https:// www.aihw.gov.au/reports/overweight-obesity/a-picture-of-overweight-andobesity-in-australia/notes
6. Lee C, Goode B, Nørtoft E, Shaw J, Magliano D, Colagiuri S. The cost of diabetes and obesity in Australia. J Med Econ. 2018;21(10):1001-5. https:// doi.org/10.1080/13696998.2018.1497641.

7. Stratton I. Association of glycaemia with macrovascular and microvascular complications of type 2 diabetes (UKPDS 35): prospective observational study. BMJ. 2000;321(7258):405-12. https://doi.org/10.1136/bmj.321.7258.405.

8. Holman R, Paul S, Bethel M, Matthews D, Neil H. 10-year follow-up of intensive glucose control in type 2 diabetes. N Engl J Med. 2008;359(15): 1577-89. https://doi.org/10.1056/NEJMoa0806470.

9. The Action to Control Cardiovascular Risk in Diabetes Study Group. Effects of intensive glucose lowering in type 2 diabetes. N Engl J Med. 2008;358(24):2545-59.

10. Lean MEJ, Leslie W, Barnes A, Brosnahan N, Thom G, McCombie L, et al. Primary care-led weight management for remission of type 2 diabetes (DiRECT): an open-label, cluster-randomised trial. Lancet. 2018;391(10120): 541-51. https://doi.org/10.1016/S0140-6736(17)33102-1.

11. Taheri S, Zaghloul H, Chagoury O, Elhadad S, Ahmed S, El Khatib N, et al. Effect of intensive lifestyle intervention on bodyweight and glycaemia in early type 2 diabetes (DIADEM-I): an open-label, parallel-group, randomised controlled trial. Lancet Diabetes Endocrinol. 2020;8(6):477-89. https://doi. org/10.1016/S2213-8587(20)30117-0.

12. Wing R, Bolin P, Brancati F, Bray G, Clark J, Coday M, et al. Cardiovascular effects of intensive lifestyle intervention in type 2 diabetes. N Engl J Med. 2013;369(2):145-54. https://doi.org/10.1056/NEJMoa1212914.

13. Lih A, Pereira L, Bishay R, Zang J, Omari A, Atlantis E, et al. A novel multidisciplinary intervention for long-term weight loss and Glycaemic control in obese patients with diabetes. J Diabetes Res. 2015;2015:1-7. https://doi.org/10.1155/2015/729567.

14. Sharples A, Mahawar K. Systematic review and meta-analysis of randomised controlled trials comparing long-term outcomes of roux-en-y gastric bypass and sleeve gastrectomy. Obes Surg. 2020;30(2):664-72. https://doi.org/10.1 007/s11695-019-04235-2

15. Adams T, Davidson L, Litwin S, Kim J, Kolotkin R, Nanjee M, et al. Weight and metabolic outcomes 12 years after gastric bypass. N Engl J Med. 2017; 377(12):1143-55. https://doi.org/10.1056/NEJMoa1700459.

16. Jans A, Näslund I, Ottosson J, Szabo E, Näslund E, Stenberg E. Duration of type 2 diabetes and remission rates after bariatric surgery in Sweden 20072015: a registry-based cohort study. PLoS Med. 2019;6(11):e1002985.

17. Davies M, D'Alessio D, Fradkin J, Kernan W, Mathieu C, Mingrone G, et al. Management of hyperglycaemia in type 2 diabetes, 2018. A consensus report by the American Diabetes Association (ADA) and the European Association for the Study of diabetes (EASD). Diabetologia. 2018;61(12): 2461-98. https://doi.org/10.1007/s00125-018-4729-5.

18. Simmons D, Wenzel H, Zgibor J. Integrated diabetes care: a multidisciplinary approach cham: Springer International Publishing; 2016. https://doi.org/10.1 007/978-3-319-13389-8.

19. Zarora R, MacMillan F, Piya M, Fernandes B, Simmons D. Effectiveness of a locality-based integrated diabetes care service on clinical outcomes. Intern Med J. 2021. https://doi.org/10.1111/imj.15211.

20. Clinical Practice Guidelines for the management of overweight and obesity | NHMRC. Nhmrc.gov.au. 2013 [cited 6 August 2020]. Available from: https:// nhmrc.gov.au/about-us/publications/clinical-practice-guidelines-mana gement-overweight-and-obesity

21. Obesity: identification, assessment and management | Guidance and guidelines | NICE [Internet]. Nice.org.uk. 2014 [cited 6 August 2020]. Available from: https://www.nice.org.uk/guidance/cg189/chapter/1-recommendations

22. Rubino F, Nathan D, Eckel R, Schauer P, Alberti K, Zimmet $P$, et al. Metabolic surgery in the treatment algorithm for type 2 diabetes: a joint statement by international diabetes organizations. Diabetes Care. 2016;39(6):861-77. https://doi.org/10.2337/dc16-0236.

23. Bariatric Service Registry. Public Health and Preventative Medicine. 2019 [cited 6 August 2020]. Available from: https://www.monash.edu/_data/assets/pdf_ file/0006/1953438/316765-Bariatric-Surgery-Registry-2019_FINALv3WEB-.pdf

24. Atlantis E, Kormas N, Samaras K, Fahey P, Sumithran P, Glastras S, et al. Clinical obesity services in public hospitals in Australia: a position statement based on expert consensus. Clinical Obesity. 2018;8(3):203-10. https://doi. org/10.1111/cob.12249.

25. Daousi C, Casson I, Gill G, MacFarlane I, Wilding J, Pinkney J. Prevalence of obesity in type 2 diabetes in secondary care: association with cardiovascular risk factors. Postgrad Med J. 2006;82(966):280-4. https://doi.org/10.1136/pmj.2005.039032.

26. NHS. National Diabetes Audit, 2017-18 Report 2b: Complications and Mortality. Files.digital.nhs.uk. 2019 [cited 6 August 2020]. Available from: 
https://files.digital.nhs.uk/64/OAFA78/National\%20Diabetes\%20Audit\%2C\%2 02017-18\%2C\%20Report\%202b.pdf

27. Amin A, Ali A, Altaf Q, Piya M, Barnett A, Raymond N, et al. Prevalence and associations of obstructive sleep apnea in south Asians and white Europeans with type 2 diabetes: a cross-sectional study. J Clin Sleep Med. 2017;13(04):583-9. https://doi.org/10.5664/jcsm.6548.

28. Pinzur $M$, Freeland $R$, Juknelis $D$. The association between body mass index and foot disorders in diabetic patients. Foot Ankle Int. 2005;26(5):375-7. https://doi.org/10.1177/107110070502600506.

29. Wharton S, Serodio K, Kuk J, Sivapalan N, Craik A, Aarts M. Interest, views and perceived barriers to bariatric surgery in patients with morbid obesity. Clin Obes. 2016;6(2):154-60. https://doi.org/10.1111/cob.12131.

30. Craig H, le Roux C, Keogh F, Finucane F. How ethical is our current delivery of care to patients with severe and complicated obesity? Obes Surg. 2018; 28(7):2078-82. https://doi.org/10.1007/s11695-018-3301-1.

31. Medveczky D, Kodsi R, Skelsey K, Grudzinskas K, Bueno F, Ho V, et al. Class 3 obesity in a multidisciplinary metabolic weight management program: the effect of preexisting type 2 diabetes on 6-month weight loss. J Diabetes Res. 2020;2020:1-9. https://doi.org/10.1155/2020/9327910.

32. Schauer P, Bhatt D, Kirwan J, Wolski K, Aminian A, Brethauer S, et al. Bariatric surgery versus intensive medical therapy for diabetes -5 -year outcomes. N Engl J Med. 2017:376(7):641-51. https://doi.org/10.1056/NEJMoa1600869.

33. Carlsson L, Sjöholm K, Karlsson C, Jacobson P, Andersson-Assarsson J, Svensson $\mathrm{P}$, et al. Long-term incidence of microvascular disease after bariatric surgery or usual care in patients with obesity, stratified by baseline glycaemic status: a post-hoc analysis of participants from the Swedish obese subjects study. Lancet Diabetes Endocrinol. 2017;5(4):271-9. https:// doi.org/10.1016/S2213-8587(17)30061-X.

34. Bramante C, Lee C, Gudzune K. Treatment of obesity in patients with diabetes. Diabetes Spectrum. 2017;30(4):237-43. https://doi.org/10.2337/ds1 7-0030.

35. Australian Government Department of Health. Australian National Diabetes Audit Annual report: Monash University; 2019. [cited 6 August 2020]. Available from: https:/nadc.net.au/wp-content/uploads/2020/03/ANDA-A QCA-2019-Annual-Report.pdf

\section{Publisher's Note}

Springer Nature remains neutral with regard to jurisdictional claims in published maps and institutional affiliations.

Ready to submit your research? Choose BMC and benefit from:

- fast, convenient online submission

- thorough peer review by experienced researchers in your field

- rapid publication on acceptance

- support for research data, including large and complex data types

- gold Open Access which fosters wider collaboration and increased citations

- maximum visibility for your research: over $100 \mathrm{M}$ website views per year

At $\mathrm{BMC}$, research is always in progress.

Learn more biomedcentral.com/submissions 